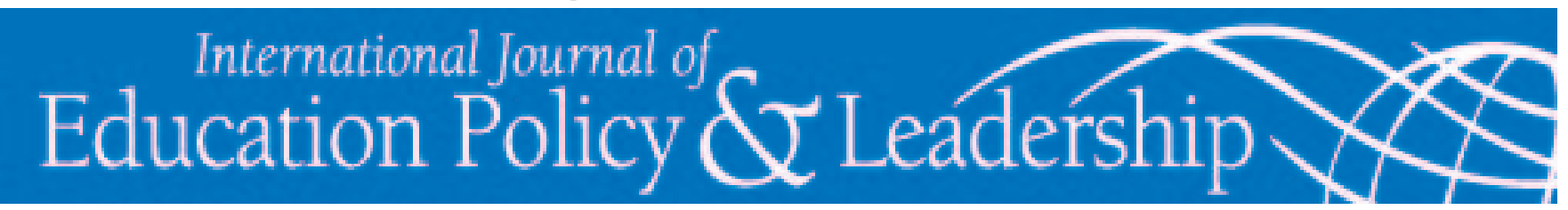

\title{
An Analysis of How the Gender and Race of School Principals Influences Their Perceptions of Multicultural Education
}

\author{
Carlos R. McCray, ED. D \\ Georgia State University \\ Floyd D. BEACHUm, ED.D. \\ Lehigh University
}

\begin{abstract}
The purpose of this study was to investigate secondary school principals' perceptions of multicultural education in a rural southeastern state. The researchers wanted to ascertain whether or not the race or gender of school principals have a role in how those principals view multicultural education in theory (its theoretical value). For the purpose of this study, multicultural education in theory was defined as the belief that multicultural education is for all students, elevates students' self-esteem, is embedded in cultural pluralism, and recognizes the social, political, and economic community and societal constructs on students of color (Fernandez, 1996). Three hundred and two secondary school principals were surveyed in a designated southeastern state. A significant difference was discovered with regard to the gender of the school principals and their perceptions of the theoretical value of multicultural education.
\end{abstract}

McCray, C. \& Beachum, F. (2010). An Analysis of How the Gender and Race of School Principals Influences Their Perceptions of Multicultural Education. International Journal of Education Policy and Leadership 5(4). Retrieved [DATE] from http://www.ijepl.org.

\section{Introduction}

The Declaration of Independence affirms every individual's God-given right to "life, liberty, and the pursuit of happiness." But even as the Founding Fathers proclaimed that all human beings possessed these inalienable rights, they knew that the reality of American society contradicted their proclamation. There have been many contradictions between rhetoric and reality throughout this country's history regarding human rights. The American creed calls for all men (individuals) to be treated equally and given the right to life, liberty, and the pursuit of happiness. One of the most obvious examples of many Americans' indifference to the American creed concerns public education. For the first half of this country's history, public education was available principally to those of European descent, which affected the ability of certain groups to achieve their dreams and goals in America (Nisbett, 2009; Yeo
\& Kanpol, 1999). Nonwhites were barred by most states from a tax-supported education, and even when they received access to schooling in private institutions, the course of study was entirely European-based (Bhavnagri \& Prosperi, 2007; Smith, 1998; Ward, 1991).

As America progressed in its effort to provide African Americans with an education, particularly in the latter part of the 19th century through the early 20th century, educational Jim Crow laws were entrenched, leading to supposedly "separate but equal" schools among blacks and whites (Patterson, 2001). In this era of schooling for African Americans, many of the students were presented opportunities to learn a great deal about their heritage because of the hard work of such individuals as Carter G. Woodson. Woodson was one of many who championed exposure for African Americans to a school curriculum that reflected their heritage (Banks, 1996). With the rul-

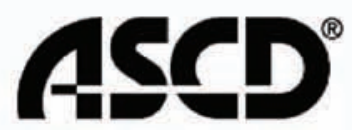

LEARN. TEACH. LEAD.
SIMON FRASER UNIVERSITY

THINKING OF THE WORLD

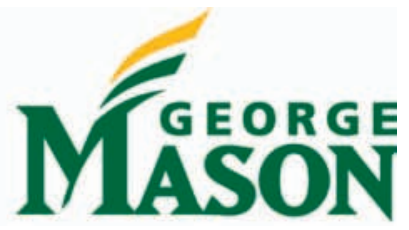


ing of Brown v. Board of Education in 1954, many schools around the United States, especially in the Deep South, began to incrementally integrate their school facilities, a concept known as gradualism (Ferri \& Connor, 2005). When the gradualist approach to school integration finally collapsed due to progressive court cases-for example, in Swann v. Charlotte-Mecklenburg Board of Education (Patterson, 2001)_African American students saw a void in the school's curriculum with regard to their heritage and history (Asante, 1991; Asante, 1992).

This deficiency within the curriculum of the newly integrated schools was the catalyst for the concept of multicultural education (Banks, 1996). African Americans, women, and other minority groups began to rigorously examine the content of what was being taught in schools, and they discovered that many aspects of what they considered important to their respective groups was not part of the learning experience (Asante, 1992; Banks \& Banks, 1989; Banks, 1991; Grant, 1995). During the apex of school integration in the 1970s (Patterson, 2002), multiculturalists primarily focused on making sure content integration was part of a school's curriculum (Banks \& Banks, 1989). Unfortunately, the idea of implementing any form of a multicultural curriculum in schools was not the main priority of many school administrators, especially in schools in the Deep South. In fact, some of the administrators' goals during the apex of school integration were to prevent the formation of a unitary school system (McCray, Alston, \& Beachum, 2006). Capper (1993) observed that, even today, "to some administrators, the idea of education that is multicultural and social reconstructionist conjures up images of teaching their students how to be radical student demonstrators, reminiscent of the sixties" (p. 288).

\section{Purpose of the Study}

Just as it seemed America was making significant progress in dealing with the issues of racism, sexism, and other forms of bigotry, in recent years there have been a plethora of issues that have arisen to remind us that we still need multicultural education to fight intolerance and prejudice. One such incident was the Jena episode, which will be expanded on later in the article. McCray, Wright, and Beachum (2004) posited that "it is the school principal who sets the tone of the school culture and provides the proper vision as to the direction of the institution" (p. 111). Indeed, there is an increasing amount of diversity that is accruing in our country and the southeastern state where this study took place. Also, due to the seeming lack of interest by many public education systems in addressing issues of diversity, this study examined principals' perceptions of multicultural education to determine whether their perceptions differ based on certain personal characteristics (i.e., race and gender). The researchers purport that since the school principal sets the tone of the school culture and provides vision and direction (McCray, Wright, and Beachum, 2004), an investigation into the personal characteristics of principals is justified to determine any potential biases as they relate to multiculturalism.

Multicultural education in this study is being conceptualized through its theoretical perspective, the ideological and philosophical belief concerning multiculturalism. This theoretical perspective entails the belief that multicultural education is for all students, elevates students' self-esteem, is embedded in cultural pluralism, and recognizes the social, political, and economic community and societal constructs on students of color (Fernandez, 1996). Indeed, the scope of multicultural education goes beyond how the authors have chosen to conceptualize it here. When multicultural education is examined in its totality, there is an educational value (i.e., equity pedagogy, content integration, and knowledge construction) as well as a school climate value, which emphasizes prejudice reduction among faculty and staff as well as students (Banks \& Banks, 2006). However, for the purpose of this article, the authors have chosen to focus on how school administrators view multiculturalism from an ideological and philosophical stance. As the nation becomes more racially diverse, students need a form of education where the concepts of caring, fairness, and equity are embedded in the schooling process (Banks, 1995). Thus, this inquiry will help educational administration preparation programs, as well as administrators themselves, to understand how the issue of multicultural education is being perceived in this designated southeastern state. And we hope the study will allow for such preparation programs and administrators to make any needed adjustments to promote a more positive learning environment for students of different social and cultural backgrounds.

\section{Context}

\section{Cultural Pluralism and Multicultural Education}

In order for the theoretical construct to become operationalized in the school's culture, educators and school 
officials must be cognizant of oppressive policies that are embedded within the school. Racism and other forms of discrimination are some of the main causes of oppressive policies in schools and other institutions (Feagin, 2006; Nieto \& Bode, 2008). Oppressive policies may instill in students who belong to certain disenfranchised or marginalized groups feelings of dejection, rejection, and unsteadiness (Feagin, 2006; Harro, 2000; Nieto \& Bode, 2008). This sense of dejection can have a major influence on students' ability to comprehend their own identity and maintain their sense of self-worth within the school culture and society at large. (Beachum \& McCray, 2004). Oppressive policies, whether they are de facto or de jure (de facto refers to unwritten rules, while de jure appertains to written policies), can affect the theoretical constructs of multicultural education. For example, if students feel that their cultures and ways of seeing the world are not validated and are looked upon from a deficit standpoint (Solorzano, 1997), this will undoubtedly affect how they interpret such concepts as fairness, caring, and equality.

Oppressive policies in schools usually come in the disguise of maintaining the status quo (Ferguson, 2001). Alas, the concept of cultural pluralism is many times superseded by this. Gordon (1978) indicated that "cultural pluralism involves giving and taking and, more importantly, the sharing of and mutual respect for ideas, customs and values" (p. 64). Cox (1994) opined that "pluralism refers to a two-way learning and adaptation process in which both the organization and entering members from various cultural backgrounds change to some degree to reflect the cultural norms and values of the other" (p. 167). We have chosen Cox and Gordon's definition of cultural pluralism to illustrate how multiculturalism addresses the social, political, and economic effects that diversity has on communities and on society as a whole.

One way oppressive policies can be diminished is through the embracing of cultural pluralism. Cultural pluralism requires individuals from different backgrounds to make an effort to understand one another. Phuntsog (1995) opined that America is made up of many different cultures, and that it is the multicultural education approach that wholeheartedly embraces cultural pluralism. Consequently, K-12 schools should be cautious concerning "the one size fits all" assimilation process to create a façade of homogeneity in the hopes that the complex identities of individuals will simply disappear. Such an approach is contrary to cultural plural- ism. Carter, Chinn, Perkins, and Thomas (1994) indicated concern that educators and administrators are not implementing multicultural education with the underpinnings of cultural pluralism and that the implementation of multicultural education at some schools can, paradoxically, promote inequalities among the students.

Carter et al. (1994) found that many educators utilize multicultural methods that promote inequalities via three methods-the missionary approach, the minstrel approach, and the tolerance approach.

The missionary approach involves educators' belief that students of color come from a disadvantaged culture, and that the educators' job is to bring these students up to speed with the mainstream culture. According to Carter et al., "Instead of operating from the perception that the students themselves are deficient...educators should scrutinize the instruction and curricula in order to assess and correct inadequacies there" (Carter et al., 1994, p. 462).

The minstrel approach involves educators making an attempt to incorporate various cultures into the mainstream culture. However, the cultures of students of color are not presented in a realistic and truthful wayin some cases, they are presented in a burlesque manner.

The tolerance approach occurs when educators teach students that diversity is something that should be tolerated rather than truly valued. The problem with this approach is that students do not learn to appreciate other cultures that might be different from their own, a concept that is at the center of multicultural education (Carter et al., 1994).

Undoubtedly, each of these approaches is still being used by educators and administrators alike in the hope of creating the impression that they are making an earnest effort to be inclusive and value diversity (Asante, 1991; Ferguson, 2001; Carter, et. al., 1994; Solorzano, 1997). However, in the meantime, while educators and administrators are trying to perfect such an appearance, students of color are still being suspended and expelled at alarming rates (McCray \& Beachum, 2006) as well as being misidentified, misassessed, mislabeled, and misplaced into inappropriate educational tracks (Obiakor, Harris-Obiakor, Garza, Nelson, \& Randall, 2005).

The aforementioned methods do not promote cultural pluralism and, as noted, can harm efforts to ensure that all students feel a sense of belonging within the school. Banks (2004) opined that a major benefit of multicultural education is the value that is placed on the appreciation of diversity. This allows students to under- 
stand each other's cultures better. It allows students to appreciate diversity on a much higher level. This type of appreciation is needed to foster our democratic values, which is one of the most important goals of education (Banks, 2004).

Despite the notion that cultural pluralism is necessary to promote cultural and social diversity, many educators and administrators have still not been persuaded by the ideals of it. In fact, Dantley (2002) indicated that multicultural education has been co-opted and has lost its radical quality in order to appease would-be detractors. Sleeter (1996) has also raised concerns that some multicultural theorists have begun to compromise the basic foundation of multicultural education in order to appease opponents who intend to maintain the status quo. According to Taylor (2000),

Although grounded in an era of change and vision of equality, [multiculturalism] has seen its goals diluted. Its original activist agenda has been diminished as the political climate shifts toward "color blindness" and attempts at an inclusive curriculum are reduced to cultural tourism. Some adherents believe that for multiculturalism to reassert its relevancy, it must openly identify oppression and struggle against it more explicitly. (p. 540)

Sleeter (1996) has found that the issue of race should be at the forefront of multicultural education. Antidiscrimination policies and programs should take into account the issues of race, since it is still linked to the "master identity" (Lacy, 2007) in the form of discrimination in our society (Back \& Solomos, 2000; Lacy, 2007). This master identity disproportionately serves "European American, upper-middle class, English speaking, and male" individuals within our society (Nieto, 2000 , p. 35). In essence, this master identity construct serves to maximize the cultural and social capital (Loury, 2002) for those who fit a certain societal criteria (Lacy, 2007; Rothenberg, 1998). And the event that took place in rural Jena, Louisiana, is an incredible example of the need to continue to focus on the subject of racism when we address multiculturalism.

The Jena controversy took place in 2006, when six black teenagers were charged with assaulting a white teenager. It was later found that racial tension had been building as a result of a noose being placed on a tree to intimidate the black teenagers from socializing in the shade. The incident made national news and created outrage all across the country.
Because of such incidents, and the increasing amount of diversity in the U.S., the researchers set out to determine to what extent personal characteristics of secondary school principals (i.e., race and gender) influence their perceptions of the theoretical values of multicultural education in a designated southeastern state. The authors intend the information gathered from this study to help school administrators and educators better understand how personal characteristics impact perceptions of diversity, and hopefully to provide an understanding of how to move forward in the endeavor of providing the "transformative curriculum for empowerment" that Banks (2004) argues for in a multicultural society.

\section{Methodology}

\section{Participants and Procedures}

In this study, the researchers mailed all secondary school principals in the designated southeastern state a copy of the survey. A total of 302 surveys were mailed out to principals, with a return rate of 42 percent $(\mathrm{N}=126)$. This return rate was determined to be a "reasonably good return rate" (Mertler \& Charles, 2008, p. 240) and acceptable for statistical analyses (Fraenkel \& Wallen, 2000; Haller \& Kleine, 2001). The school addresses of these principals were acquired through the State Department of Education educational directory. In this state, secondary education included the following grade levels: 7-12, 8-12, 9-12, and 10-12. Certain counties in the state did not have schools that were represented in the aforementioned grade level categories. Therefore, these schools were grouped into the category of comprehensive schools (grades 1-12). This methodology produced the total number of 302 schools for the study. The number of respondents was tallied once all the surveys were received. A thorough examination was conducted to ascertain where the respondents of the survey were located to ensure that each geographical region in the state was represented. It was concluded that all the geographical regions of the state were represented in the 126 responses.

As indicated above, the goal of this study was to determine whether there were any differences in secondary school principals' perceptions concerning the theoretical constructs of multicultural education as it relates to their personal characteristics (in this case, the researchers looked at the administrators' gender and race). Although other information was obtained from the 
survey concerning the principals' years of administrative experience, number of professional diversity workshops, and educational achievement, this information was categorized as professional information and not designated as personal characteristics. Of the respondents to the study, 79.4 percent were male principals, and 20.6 percent were female principals. These percentages also reflect the representation of all female and male principals as reported by the state's Department of Education. Female principals in the state represented 16 percent of all the secondary principals in the state.

In order to determine the administrators' race, administrators in the state were asked to select their race from the following categories: European American, African American, Hispanic American, Asian American, and Native American. Table 1 summarizes the description of respondents concerning their race. Responses regarding race of the principals paralleled the 2000 U.S. Census data of the state. The census indicated that whites accounted for 71.1 percent of the population in the state; African Americans accounted for 26 percent; the Hispanic population accounted for 1.7 percent, and Asian Americans and Native Americans accounted for 1.2 percent combined. These statistics were similar to those who responded to the survey, with 72.2 percent of secondary principals being white and 22.2 percent African American. As indicated, Native Americans and Asian Americans make up only 1.2 percent of the total population in the state; however, they made up 5.6 percent of the number of principals who responded to the survey.

\section{Survey Instrument}

This study used a four point Likert-type scale survey to measure high school principals' perceptions of the theoretical value of multicultural education. The instrument for this study consisted of two parts. Part one of the sur-

\begin{tabular}{|c|c|c|}
\hline Girnup & Trequenty & Percenil \\
\hline Eurupsant Anterican & 91 & 72.2 \\
\hline African Ancrican & 28 & 22.2 \\
\hline Hispunic American & n & 0 \\
\hline Asian American & 0) & 0 \\
\hline Native Ancrican & 7 & 5.6 \\
\hline Iotal & 126 & 100.0 \\
\hline
\end{tabular}

vey consists of 13 specific questions that were designed to obtain personal and professional information from the principals, as well as school and demographic information. Survey items 1, 2, 3, 12, and 13 investigated the principals' personal and professional characteristics. These question items addressed the following concerning the administrators: educational attainment, gender, years of experience, number of workshops attended, and ethnic origin. Survey items 4, 5, 6, and 7-11 addressed the school's geographical location (urban, suburban, and rural), socioeconomic status of the school, and the school's racial makeup.

The second part of the survey utilized a four point Likert-type rating scale (Strongly Disagree, Disagree, Agree, Strongly Agree), and dealt with ascertaining principals' perceptions of the theoretical constructs of multicultural education. Question items 6, 12, 13, 15, 16, and 17 addressed principals' understanding of the theoretical value of multicultural education. As previously stated, the theoretical construct was defined as the belief that multicultural education is for all students, elevates students' self-esteem, is embedded in cultural pluralism, and recognizes the social, political, and economic community and societal constructs on students of color (Fernandez, 1996). The survey design allowed the researcher to draw inferences from the sample concerning the entire population of principals in the identified state (Fraenkel \& Wallen, 2000). Thus, this study set out to determine whether principals' perceptions of the theoretical value of multicultural education differ by gender and race.

\section{Validity and Reliability}

This survey instrument was originally used by Fernandez (1996) and Dees (1993). Fernandez reported the internal consistency by using Cronbach's alpha coefficient. This technique uses a cross-sectional analysis of data gathered to measure the internal reliability coefficients of the instrument. When an instrument's alpha is relatively high, .70 or greater, the variance that existed in the instrument can be the result of general and group factors rather than item-specific variance (Cortina, 1993). The alpha coefficient for the theoretical value subscale was .87. Construct validity evidence is provided via the theoretical discussion that Fernandez (1996) and Dees (1993) have indicated vis-à-vis the high internal consistency correlation obtained with Cronbach's Alpha 
correlation. This shows that the instrument is a valid and reliable instrument for the purpose of the study. The content validity was obtained by Dees (1993), wherein experts examine the representativeness of the items that made up the scale. Although Fernandez does not explicitly state the validity procedure of the instrument, there is enough evidence gained through the theoretical research to show validity.

\section{Findings}

One-way analysis of variance (ANOVA) tests were used to ascertain principals' perceptions of the theoretical values of multicultural education based on the principals' gender. The ANOVA procedure for this particular test yielded a statistical significance between males and females ( F1, $124=5.436, \mathrm{p}<.05)$. Further investigation showed that males had a higher mean on the theoretical construct of multicultural education, indicating more agreement with the statements on the scale than females. Results of the ANOVA are summarized in Table 2.

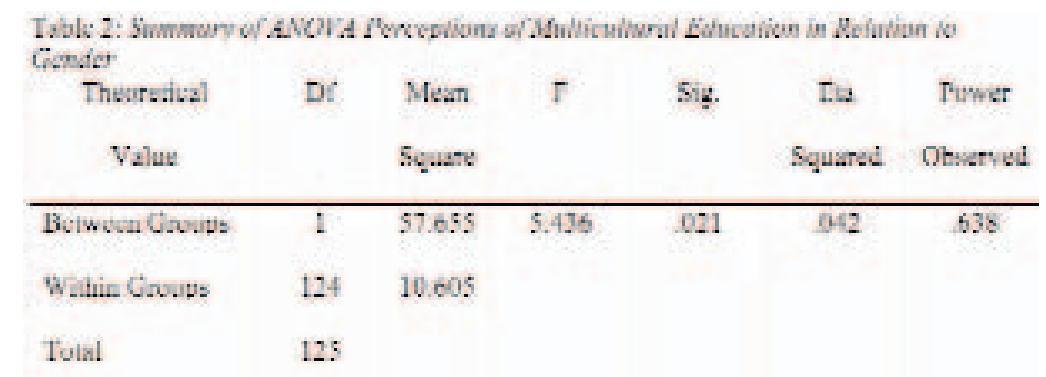

\section{Race of the Principal}

One-way analysis of variance (ANOVA) tests were used to ascertain principals' perceptions of the theoretical construct of multicultural education in relation to the principals' race. The ANOVA procedure for this particular test did not yield any statistical differences between principals' ethnicity.

\section{Discussion}

A statistically significant difference was found between male and female principals' views of the theoretical construct of multicultural education ( F1, $124=5.436$, p < .05). Principals' perceptions of the theoretical construct of multicultural education were influenced by their gender. The male principals believed more than the female principals that multicultural education should be made available for all students, elevate the students' selfesteem, emanate from cultural pluralism, and help in understanding the social, political, and economic effects of society and schools on students of color. Within the context of our designated southeastern state, it could be construed that the male principals, due to more years of experience, had a better understanding of the theoretical constructs of multicultural education. To support this argument even further, the Pearson's Product Moment correlation data that is provided in Table 3 (page 7) indicated that the males in the study had significantly more years of administrative experience than the females in the study ( $\mathrm{r}=-.233, \mathrm{p}<.01$, two tailed).

\section{Pearson's Product Moment Correlations}

As is seen in Table 3, there are no other strong correlations with gender that would allow an inference to be drawn as to why male principals had a more favorable view of the theoretical value of multicultural education than female principals. There were no such strong correlations with gender and the level of education of the school principal, the school setting, the size of the school, the racial makeup of the school, or the race of the administrators.

However, something else that is worthy of note is the high variance among female principals on the theoretical construct of multicultural education. It seems that there was not a strong consensus among female principals in our designated southeastern state as to the purpose of multicultural education in theory. This could be interpreted as females showing more effort to thoroughly conceptualize the purpose and goals of multicultural education.

Also, the theoretical construct would not call for immediate restructuring of the day-to-day operations. The theoretical construct of multicultural education has a certain abstraction. It is a philosophical and ideological approach to multicultural education. Thus, there is a certain element of praxis embedded in the theoretical value-meaning administrators would be required to reflect more meaningfully on how they would put into practice multicultural education in their schools prior to the actual implementation. And since there was not a great variance among male principals on the theoretical value, it could be concluded that male principals were more comfortable with their interpretations of the theoretical value.

The fact that female principals might have been more willing to try to conceptualize in earnest the true underpinning of the theoretical value is grounded implicitly in the literature. Paradoxically, this effort of 


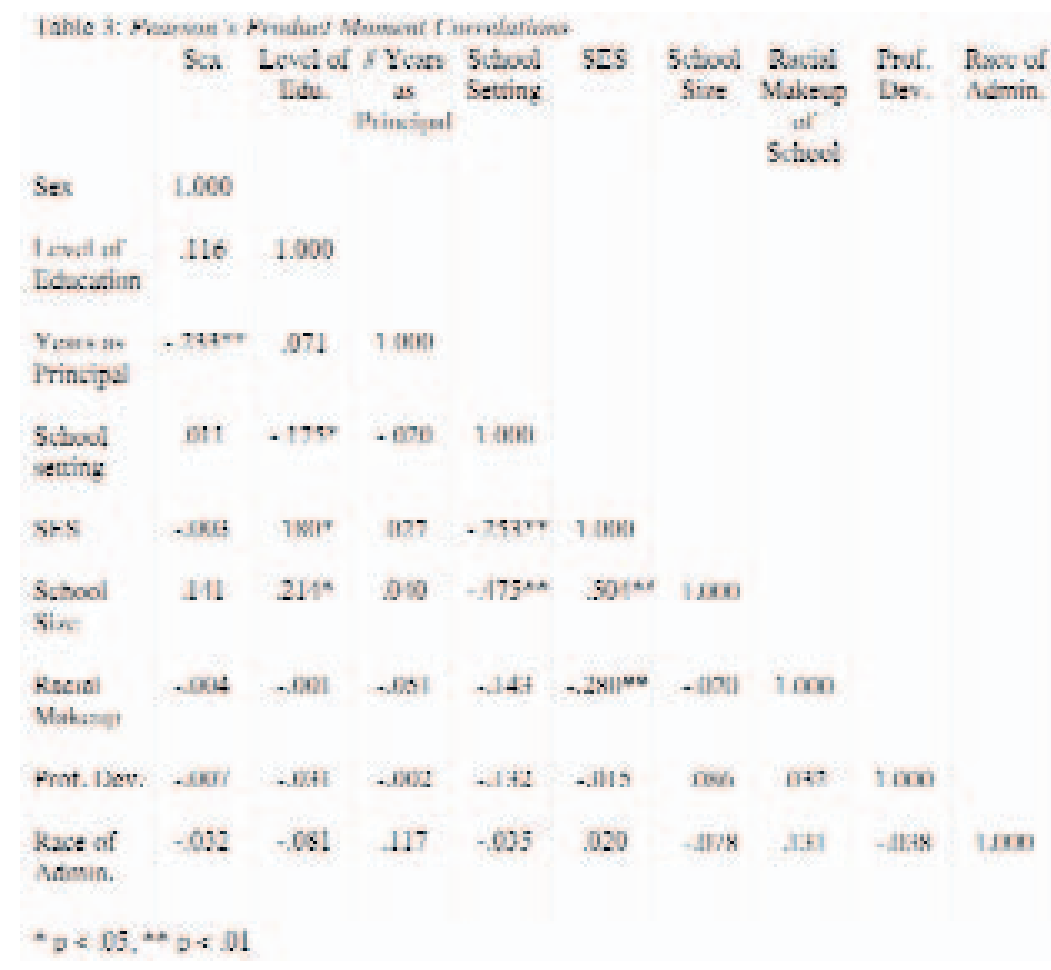

praxis could also have been due to the fewer years of experience the female principals had, overall, in comparison to the male principals. The fact that female principals had fewer years of experience and thus were probably more closely connected to the classroom (Ortiz, 1982) might have also contributed to their trying to conceptualize the true underpinnings of the theoretical purpose of multicultural education. Nevertheless, other studies would have to be conducted to substantiate this conclusion.

\section{Limitations}

Some limitations should be noted with regard to this study. The return rate was only 42 percent, which could limit the generalizability of the results. Also, the study was limited to examining only secondary school principals' perceptions of the theoretical constructs of multicultural education in our designated southeastern state. The generalizability of the results cannot be applied to elementary school principals, or principals throughout other geographical regions of the country. Another limitation of the study is that it solicited socially desirable answers from participants. There is often a disconnect between what school officials profess and what they actually practice. This research tried to unearth as much as possible about how school principals felt about the theoretical value of multiculturalism. However, in the future, research on this particular topic may want to take an approach that goes beyond survey data in ascertaining principals' perceptions of multicultural education.

Further research may entail researchers embedding themselves into the school's culture to gauge whether or not school principals are providing lip service or life service to the diversity found in their schools. This would undoubtedly give researchers a greater understanding of principals' praxis of multicultural education. Such embedding could be done by researchers by employing case study methodology, which allows the researcher to collect multiple sources of data with regard to a given phenomenon (Yin, 1994). Finally, future survey research may want to go a step further in the data analysis by determining whether the perceptions of black and white males, and black and white females, differ by race.

\section{Conclusion}

Barnhart (1996) noted that "there are many advantages gained in bringing children from all walks of life and letting them learn to live and grow together. But we must make room for greater diversity; this means we must respect the culture of different groups" (p. 24). This is indeed cultural pluralism in its purest form. Once school administrators understand the theoretical constructs of multicultural education, they must begin the collaboration stage of its implementation. The principal must use tactful skills when advocating for such a climate within the school, because of strong feelings expressed by opponents of such a transformative curriculum (Banks, 2006). It would be a great mistake for administrators to ignore multicultural issues because of potential controversy.

It is the goal of this study to help principals at the secondary level, as well as administrator preparation programs, to have a better understanding of how the theoretical value of multicultural education is being perceived in schools. According to the findings of this study, gender, along with years of administrative experience, can have an influence on how school principals interpret the purpose of multiculturalism. As the United States becomes more culturally and socially diverse than ever before, school administrators must be prepared to deal with possible cultural collisions (Beachum \& McCray, 2004), where the students' culture and the culture of the school collide. In most instances, it is the students of 
color who are marginalized even further (Ferguson, 2001).

One of the best ways to deal with increasing diversity and reduce such cultural collisions is to have an understanding of how students from historically marginalized groups make meaning of their communities, schools, society, and the world in general, which means that school administrators should have more training and access to professional development that focuses on such concepts (Gorski, 2006; Tatum, 1997). Thus, in order to provide sufficient training, professional development, and education to principals, it would be of great help to school districts and university leadership preparation programs to have knowledge of how such variables as personal characteristics of school administrators shape and influence their understanding of multicultural education. In essence, both entities (school systems and educational leadership preparation programs) should make dealing with these issues a top priority.

\section{References}

Asante, M. K. (1991). Back talk: And then there was Columbus. Essence, 144, 9.

Asante, M. K. (1992). Afrocentric curriculum. Educational Leadership, 12, 28-31.

Back, L., \& Solomos, J. (2000). Changing boundaries and spaces. In L. Back \& J. Solomos (Eds.), Theories of race and racism: A reader. New York: Routledge.

Banks, J. A. (1991). Curriculum for empowerment, action, change. In C. Sleeter (Ed.), Empowerment through multicultural education (pp. 125-141). New York: State University of New York Press.

Banks, J.A. (1995). Multicultural Education: Development, dimensions, and challenges. In J. Joll (Ed.), Taking sides: Clashing views on controversial education issues (pp. 84-93). New York: The Dushkin Publishing Group, Inc.

Banks, J. A. (1996). The African American roots of multicultural education. In J.A. Banks (Ed.), Multicultural education, transformative knowledge, and action: Historical and contemporary perspective (pp. 30-45). New York: Teachers' College Press.

Banks, J. A. (2004). Teaching for social justice, diversity, and citizenship in a global world. The Educational Forum, 68(4), 296-305.

Banks, J. A., \& Banks, C. A. M. (Eds.). (1989). Multicultural education: Issues and perspectives. Boston: Allyn \& Bacon.
Banks, J. A., \& Banks, C. A. (2006). Multicultural education: Issues and perspectives. Hoboken, NJ: Wiley.

Barnhart, J. (1996). The libertarian curriculum for public education. Free Inquiry, 16(2), 24-27.

Beachum, F.D., \& McCray, C.R. (2004). Cultural collision in urban schools, Current Issues in Education, 7(5), Retrieved February 25, 2010 from http://cie.asu.edu/volume7/number5/

Bhavnagri, N. P., \& Prosperi, J. D. H. (2007). The challenge to equality: "We made it, why can't you?" Multicultural Education, 14(3), 56-60.

Capper, C. A. (Ed.). (1993). Educational administration in a pluralistic society. Albany, NY: State University of New York Press.

Carter, D. G., Chinn, P., Perkins, F., \& Thomas, D. G. (1994). Multicultural education: Reflection on Brown at 40. The Journal of Negro Education, 63(3), 460-468.

Cortina, J. M. (1993). What is coefficient alpha? An examination of theory and applications. Journal of Applied Psychology, 78(1), 98-104.

Cox, T. H. (1994). Cultural diversity in organizations: Theory, research, and practice. San Francisco: BerrettKoehler Publishers.

Dantley, M. E. (2002). Uprooting and replacing positivism, the melting pot, multiculturalism, and other impotent notions in educational leadership through an African American perspective, 34(3), 334-352.

Dees, F. N. (1993) Perceptions of Ohio middle and junior high school principals concerning multicultural education, Michigan: UMI.

Feagin, J. R. (2006). Systemic racism: A theory of oppression. New York: Routledge.

Fernandez, G. E. (1996). Perception of Florida elementary school principals concerning multicultural education. Unpublished doctoral dissertation. University of Central Florida, Orlando.

Ferguson, A. A. (2001). Bad boys: Public school in the making of black masculinity. Ann Arbor: The University of Michigan Press.

Ferri., B. A. , \& Connor, D. J. (2005). Tools of exclusion: Race, disability, and (re)segregated education. Teachers College Record, 107(3), 453-474.

Fraenkel, J. R. \& Wallen, N. E. (2000). How to design and evaluate research in education. New York: McGraw Hill.

Gordon, M. M. (1978). Human nature, class, and ethnicity. New York: Oxford University Press. 
Gorski, P. (2006). The unintentional undermining of multicultural education: Educators at the crossroads. In J. L. Landsman \& C. W. Lewis (Eds.), White teachers/diverse classrooms: A guide to building inclusive schools, promoting high expectations, and eliminating racism (pp. 61-78). Sterling, VA: Stylus.

Grant, C. A. (1995). Reflections on the promise of Brown and multicultural education. Teachers College Record, Summer, 707-721.

Haller, E. J., \& Kleine, P. F. (2001). Using educational research: A school administrator's guide. New York: Addison Wesley Longman.

Harro, B. (2000). The cycle of socialization. In M. Adams, W. J. Blumenfield, R. Castaneda, H. W. Hackman, M. L. Peters, X. Zuniga (Eds.), Reading for diversity and social justice: An anthology on racism, anti-Semitism, sexism, heterosexism, ableism, and classism (pp. 79-82). New York: Routledge.

Lacy, K. R. (2007). Blue-chip black: Race, class, and status in the new black middle class. Berkeley, CA: University of California Press.

Loury, G. C. (2002). The anatomy of racial inequality. Cambridge, MA: Harvard University Press.

McCray, C. R., Wright, J. V., \& Beachum, F. D. (2004). An analysis of secondary school principals' perceptions of multicultural education, Education, 125(1), 111-120.

McCray, C. R., Alston, J. A., \& Beachum, F. D. (2006). Principals' perceptions of multicultural education and school climate. Multicultural Teaching and Learning, 1(1), 12-22.

McCray, C. R., \& Beachum, F. D. (2006). A critique of zero tolerance policies: An issue of justice and caring. Values and Ethics in Educational Administration, 5(1). Retrieved February 25, 2010 from

http://www.ed.psu.edu/UCEACSLE/VEEA/VEEA_Vo 15Numl.pdf

Mertler, C. A., \& Charles, C. M. (2008). Introduction to educational research (6th ed.). New York: Pearson Education, Inc.

Nieto, S. (2000). Affirming diversity: The sociopolitical context of multicultural education (3rd ed.). New York: Longman.

Nieto, S, \& Bode, P. (2008). Affirming diversity: The sociopolitical context of multicultural education (5th ed.). New York: Allyn and Bacon.
Nisbett, R. E. (2009). Intelligence and how to get it: Why schools and cultures count. New York: W. W. Norton \& Company.

Obiakor, F. E., Obiakor, P. H., Garza-Nelson, C., \& Randall, P. (2005). Educating urban learners with and without special needs: Life after the Brown case. In F. E. Obiakor \& F. D. Beachum (Eds), Urban education for the 21st century: Research,issues, and perspectives (pp. 20-33). Springfield, IL: Charles C. Thomas.

Ortiz, F. I. (1982). Career patterns in education: Women, men, and minorities in public school administration. South Hadley, MA: J. F. Bergin Publishers, Inc.

Patterson, J. T. (2001). Brown v. Board of Education: A civil rights milestone and its troubled legacy. New York: Oxford University Press.

Phuntsog, N. (1995). Teacher educators' perceptions of the importance of multicultural education in the preparation of elementary teachers. Equity and Excellence in Education, 28(1), 10-14.

Rothenberg, P. (1998). Race, class, and gender in the United States: An integrated study. (4th ed.). New York:St. Martin's Press.

Sergiovanni, T. J. (2009). The principalship: A reflective practice perspective. New York: Allyn \& Bacon.

Sleeter, C. E. (1996). Multicultural education as social activism. Albany, NY: State University of New York Press.

Smith, L. (1998). Facing slavery and ourselves: Are we ready? Social Education, 62(6), 329-332.

Solorzano, D. G. (1997). Images and words that wound: Critical race theory, racial stereotyping, and teacher education. Teacher Education Quarterly, 24(3), 5-19.

Taylor, E. (2000). Critical race theory in the backlash against affirmative action. Teachers College Record, 102(3), 539-560.

Tatum, B. D. (1997). "Why are all the black kids sitting together in the cafeteria?" and other conversations about race: A psychologist explains the development of racial identity. New York: Basic Books.

Ward, H. M. (1991). Colonial America: 1607-1763. Englewood Cliffs, NJ: Prentice Hall. 
Yeo, F., \& Kanpol, B. (1999). Introduction: Our own "peculiar institution": Urban education in 20th-century America. In F. Yeo \& B. Kanpol (Eds.), From nihilism to possibility: Democratic transformations for the inner city (pp. 1-14). Cresskill, NJ: Hampton Press, Inc.

Yin, R. K. (1994). Case study research: Design and method. Thousand Oaks, CA: Sage.

IJEPL is a joint publication of the Association for Supervision and Curriculum Development, the Faculty of Education at Simon Fraser University, and the College of Education and Human Development at George Mason University. By virtue of their appearance in this open access journal, articles are free to use, with proper attribution, in educational and other non-commercial settings 90 days after initial publication. Copyright for articles published in IJEPL is retained by the authors. More information is available on the IJEPL Web site: http://www.ijepl.org 